\title{
Rapid control of severe neoplastic hypercortisolism with metyrapone and ketoconazole
}

\section{Jean-Benoît Corcuff*, Jacques Young ${ }^{1, *}$, Pauline Masquefa-Giraud ${ }^{2}$, Philippe Chanson ${ }^{1}$, Eric Baudin ${ }^{3}$ and Antoine Tabarin ${ }^{2}$}

Department of Nuclear Medicine, Haut Lévêque Hospital, F-33604 Pessac, France, ${ }^{1}$ Department of Endocrinology, Bicêtre Hospital, F-94275 Le Kremlin-Bicêtre, France, '²Department of Endocrinology, Haut Lévêque Hospital, CHU Bordeaux, F-33604 Pessac, France and ${ }^{3}$ Department of Nuclear Medicine and Oncology, Gustave Roussy, F-94800 Villejuif, France

*(J-B Corcuff and J Young contributed equally to this work)
Correspondence should be addressed to A Tabarin Email

antoine.tabarin@ chu-bordeaux.fr

\section{Abstract}

Context: Severe Cushing's syndrome elicited by ectopic ACTH syndrome (EAS) or adrenal carcinoma (ACC) can threaten life in the short term. The effectiveness of oral administration of the inhibitors of steroidogenesis ketoconazole and metyrapone in this situation is poorly described.

Objective: To report the short-term effectiveness and tolerability of metyrapone and ketoconazole elicited either by EAS or by ACC in patients exhibiting severe hypercortisolism.

Design: Retrospective analysis of data obtained for patients with urinary free cortisol (UFC) level estimated to be fivefold the upper limit of the normal range (ULN).

Patients and settings: A total of 14 patients with EAS and eight with ACC treated in two tertiary-care university hospitals. Intervention: Metyrapone and ketoconazole treatment in combination (along with symptomatic treatments for co-morbidities).

Main outcome: Evolution of clinically relevant endpoints (blood pressure, kalaemia and glycaemia) and biological intensity of hypercortisolism 1 week and 1 month after starting steroidogenesis inhibition.

Results: After 1 week of treatment, median UFC fell from 40.0 to 3.2 ULN and from 16.0 to 1.0 ULN in patients with EAS and ACC respectively. Median UFC after 1 month of treatment was 0.5 and 1.0 ULN in patients with EAS and ACC respectively and UFC values were normal in 73 and $86 \%$ of patients respectively. Clinical status improved dramatically along with kalaemia, glycaemia and blood pressure, allowing a decrease in the relevant treatments.

Side effects were minimal and only two patients (one EAS and one ACC) experienced plasma transaminase elevations necessitating ketoconazole withdrawal.

Conclusion: Metyrapone-ketoconazole combination therapy is well tolerated and provides rapid control of endocrine cancer-related life-threatening hypercortisolism.

\section{Introduction}

Untreated or inadequately treated Cushing's syndrome (CS) is a morbid condition leading to numerous complications. The latter ultimately results in an increased mortality that is mainly due to cardiovascular events and infections. During severe CS as observed in patients with underlying neuroendocrine neoplasms responsible for ectopic adrenocorticotrophin (ACTH) syndrome (EAS) and in those with adrenal carcinomas (ACCs) (1), (c) 2015 European Society of Endocrinology Printed in Great Britain
Published by Bioscientifica Ltd. 
the catabolic and metabolic consequences of CS are exacerbated including severe hypertension, hypokalaemia, major hyperglycaemia and bedridden condition secondary to amyotrophia $(2,3,4,5,6)$. Severe hypercortisolism also favours systemic infection, sepsis due to opportunistic pathogens such as Pneumocystis carinii (7) and venous thromboembolism (8). Patients with severe hypercortisolism may experience other complications such as acute heart and respiratory failure, peritonitis due to gut perforation, pancreatitis and acute psychosis. In such instances, curative surgery of the source of ACTH secretion or of the ACC may be impossible to perform and cytotoxic chemotherapy may be associated with an increased risk of infections and death (9). Essentially, severe hypercortisolism threatens the short-term vital prognosis, pulmonary embolism and infections being significant causes of death in patients with EAS $(10,11,12)$. Surgical removal of the neoplasm responsible for CS is not always possible, either because ectopic ACTH-secreting tumours may be occult at symptom onset or because ectopic ACTH-secreting tumours and ACCs are unresectable or metastasised. Bilateral adrenalectomy (BLA) may be an option in patients with EAS, but pre-operative control of hypercortisolism may facilitate surgery and avoid perioperative complications in patients with poor overall condition (13). Otherwise, rapid correction of hypercortisolism is recommended before induction of cytotoxic chemotherapy in order to minimise the side effects of myelosuppressive cytotoxic chemotherapy (14). Thus, rapid control of hypercortisolism is mandatory to ensure short-term survival and enable medical or surgical therapies directed at the underlying tumour. Yet, very few studies have addressed this issue. Glucocorticoid receptor blockade with mifepristone has occasionally been reported to be effective (15) but is difficult to monitor and may worsen pre-existing hypertension and hypokalaemia. Inhibition of steroidogenesis with the anaesthetic drug etomidate has also been reported but its hypnotic properties limit its use (16).

Metyrapone and ketoconazole are fast-acting, orally administered drugs that inhibit distinct enzymes involved in adrenal steroidogenesis and thereby reduce cortisol production synergistically $(2,17,18,19)$. There are few published data on the treatment of severe hypercortisolism with these two drugs, alone or in combination, and this is especially true for patients with ACC. In addition, the rare published series and case reports often lack detailed information about the impact of these drugs on the magnitude of the biological response and the impact on hypercortisolism-induced morbidities such as hypertension, hypokalaemia and hyperglycaemia $(4,10,11)$.
The aim of this study was to analyse the short-term clinical and biological effectiveness and tolerability of the metyrapone and ketoconazole in a significant number of patients with severe hypercortisolism due to EAS or ACC.

\section{Patients and methods}

\section{Patients}

Data for 22 patients treated in the endocrinology departments of Bicêtre and Bordeaux university hospitals (France) were analysed. The data were collected as part of routine patient management, and local ethics committee approval was obtained for their analysis. Patients were eligible for the study if they had poor clinical status due to severe hypercortisolism related to underlying EAS or ACC. Severe hypercortisolism was defined as a mean 24-h urinary free cortisol (UFC) level $>5$ times the upper limit of the normal range (ULN) in at least three samples.

Fourteen patients (12M/2F; age 53 (24-71) years) had EAS. The ACTH-secreting tumours were: bronchial (\# 1, 2, 6 and 11) or pancreatic (\# 5, 7, 10 and 12) or thymic carcinoid tumours (\# 13), of unknown origin (metastatic neuroendocrine carcinoma, \# 8), small-cell lung carcinomas (\# 3 and 9), medullary thyroid carcinoma (\# 14), and one occult tumour (\# 4). Eight patients had cortisol-secreting ACC (2M/6F; age 60 (20-71) years). The ENSAT stages (20) were 2 and 4 in three and five patients respectively.

Complications of hypercortisolism are given in Tables 1 and 2. Briefly, 96\% of patients were hypertensive, 88\% had hypokalaemia and 75\% developed diabetes. In addition, half of the patients had at least one other severe complication due to severe CS (psychiatric disorders, opportunistic infections, phlebitis or pulmonary embolism, fractures, bedsores and bedridden status due to sarcopenia).

\section{Intervention}

All the patients received oral combination therapy with metyrapone (Metopirone $250 \mathrm{mg}$; Novartis) and ketoconazole (Nizoral 200 mg; Janssen-Cilag, Issy-les-Moulineaux, France). Metyrapone and ketoconazole were introduced either simultaneously or sequentially in the time frame of the study. Mitotane (Lysodren $500 \mathrm{mg}$; HRA-Pharma, Paris, France) was also introduced simultaneously or later in six out of 14 patients with EAS and six out of eight patients with ACC. The starting dosages were variable (median: metyrapone $2125 \mathrm{mg} /$ day and ketoconazole $900 \mathrm{mg} /$ day) and were subsequently adjusted 
Table 1 Clinical and dosage levels of patients with ectopic ACTH syndrome and adrenal carcinomas.

\begin{tabular}{|c|c|c|c|c|c|c|c|c|c|c|c|c|c|c|c|c|}
\hline \multirow[b]{2}{*}{ No. } & \multirow[b]{2}{*}{ Tumour } & \multirow[b]{2}{*}{ Sex } & \multirow{2}{*}{$\begin{array}{c}\text { BMI } \\
\left(\mathrm{kg} / \mathrm{m}^{2}\right)\end{array}$} & \multirow{2}{*}{$\begin{array}{c}\text { Age } \\
\text { (years) }\end{array}$} & \multirow[b]{2}{*}{ HT } & \multirow{2}{*}{$\begin{array}{c}\text { Low } \\
\mathbf{K}^{+}\end{array}$} & \multirow[b]{2}{*}{ DM } & \multicolumn{3}{|c|}{ Ketoconazole dosage } & \multicolumn{3}{|c|}{ Metyrapone dosage } & \multicolumn{3}{|c|}{ Lysodren dosage } \\
\hline & & & & & & & & T0 & W1 & M1 & TO & W1 & M1 & T0 & W1 & M1 \\
\hline 1 & $\mathrm{BCa}$ & M & 25.8 & 23.9 & Yes & Yes & Yes & 1000 & 1000 & 1000 & 1000 & 1000 & 2000 & 0 & 0 & 0 \\
\hline 2 & $\mathrm{BCa}$ & $\mathrm{M}$ & 24.3 & 28.5 & No & Yes & No & 1000 & 1000 & 1000 & 1000 & 1000 & 1000 & 0 & 0 & \\
\hline 3 & SCLC & $\mathrm{M}$ & 26.6 & 57.5 & Yes & Yes & Yes & 1200 & 1200 & - & 3000 & 3000 & - & 3000 & 3000 & - \\
\hline 4 & Unk & $\mathrm{M}$ & 28.0 & 51.7 & Yes & Yes & Yes & 1000 & 1000 & 1000 & 3000 & 3000 & 3000 & 3000 & 3000 & 3000 \\
\hline 5 & $\mathrm{PCa}$ & $F$ & 22.7 & 39.6 & Yes & Yes & Yes & 800 & 800 & 800 & 1500 & 1500 & 1500 & 0 & 0 & 0 \\
\hline 6 & $\mathrm{BCa}$ & $\mathrm{M}$ & 30.0 & 35.1 & Yes & No & Yes & 800 & 800 & 800 & 500 & 500 & 500 & 0 & 0 & 0 \\
\hline 7 & $\mathrm{PCa}$ & $\mathrm{M}$ & 35.3 & 53.8 & Yes & Yes & Yes & 1000 & 0 & 0 & 1500 & 1500 & 2250 & 0 & 0 & 4000 \\
\hline 8 & NET & $\mathrm{M}$ & & 60.2 & Yes & Yes & Yes & 1000 & 1200 & 1200 & 1500 & 3000 & 3000 & 0 & 0 & 1500 \\
\hline 9 & SCLC & M & 32.0 & 47.8 & Yes & Yes & Yes & 1000 & 1000 & 600 & 3000 & 3000 & 2250 & 0 & 0 & 0 \\
\hline 10 & PCa & M & 23.6 & 57.7 & Yes & Yes & Yes & 400 & 400 & 400 & 2750 & 2750 & 2750 & 0 & 0 & 2500 \\
\hline 11 & $\mathrm{BCa}$ & M & 27.0 & 64.0 & Yes & Yes & Yes & 0 & 1200 & 1200 & 3000 & 3000 & 3000 & 0 & 0 & 2000 \\
\hline 12 & PCa & $\mathrm{M}$ & 30.0 & 50.9 & Yes & Yes & Yes & 800 & 800 & 800 & 0 & 0 & 2250 & 0 & 0 & \\
\hline 13 & $\mathrm{TCa}$ & $\mathrm{F}$ & 26.0 & 69.7 & Yes & Yes & Yes & 0 & 1200 & 1200 & 3000 & 3000 & 3000 & 0 & 0 & 0 \\
\hline 14 & MTC & $M$ & 25.0 & 71.3 & Yes & Yes & Yes & 0 & 800 & 800 & 4000 & 40 & 4000 & 0 & 0 & 0 \\
\hline Median & & & 26.6 & 52.8 & & & & 900 & 1000 & 800 & 2125 & 2875 & 2250 & 0 & 0 & \\
\hline 1 & & $\mathrm{~F}$ & & & Yes & Yes & No & 1000 & & 0 & & & 0 & 0 & 0 & 3000 \\
\hline 2 & $A C C$ & $M$ & 30.5 & 60.9 & Yes & No & Yes & 800 & 800 & 800 & 3000 & 30 & 3000 & 1500 & 1500 & 3000 \\
\hline 3 & $A C C$ & $M$ & 32.0 & 65.4 & Yes & Yes & Yes & 1200 & 1200 & 1200 & 2000 & 2000 & 3000 & 4500 & 4500 & 6000 \\
\hline 4 & $A C C$ & $\mathrm{~F}$ & 27.4 & 33.8 & Yes & Yes & No & 1000 & 1000 & 1000 & 1500 & 1500 & 2250 & 0 & 1500 & 4500 \\
\hline 5 & $A C C$ & $\mathrm{~F}$ & 37.5 & 32.8 & Yes & No & No & 1200 & 1200 & 1200 & 4500 & 4500 & 3000 & 0 & 0 & 0 \\
\hline 6 & $A C C$ & $\mathrm{~F}$ & 25.6 & 60.6 & Yes & Yes & No & 1000 & 100 & 1000 & 750 & 750 & 2250 & 2000 & 2000 & 3500 \\
\hline 7 & $A C C$ & $\mathrm{~F}$ & & 60.1 & Yes & Yes & No & 1000 & 1000 & 1000 & 750 & 750 & 750 & 2000 & 2000 & 2000 \\
\hline 8 & $A C C$ & $\mathrm{~F}$ & 29.0 & 70.9 & Yes & Yes & Yes & 600 & 600 & 600 & 3000 & 3000 & 3000 & 0 & 0 & \\
\hline Median & & & 29.0 & 60.4 & & & & 1000 & 1000 & 1000 & 1750 & 1750 & 2625 & 750 & 1500 & 3000 \\
\hline
\end{tabular}

BCa, bronchial carcinoid tumours; PCa, pancreatic carcinoid tumours; TCa, thymic carcinoid tumours; SCLC, small-cell lung carcinoma; Unk, unknown; NET, neuroendocrine carcinoma; MTC, medullary thyroid carcinoma; T0, initiation of anticortisolic treatment; W1 and M1, 1 week and 1 month after initiation of anticortisolic treatment respectively; $\mathrm{HT}$, hypertension; Low $\mathrm{K}^{+}$, hypokalaemia; DM, diabetes mellitus; Compl ${ }^{\circ}$ clinical complications: one phlebitis or pulmonary embolism, two opportunistic infections, three severe psychiatric disorders, four bedridden status due to sarcopenia, five bedsores, six acute cardiovascular disorders.

according to clinical severity, UFC excretion and adverse effects. Oral hydrocortisone replacement therapy was sometimes used to prevent iatrogenic adrenal insufficiency or when serum cortisol levels were subnormal. Follow-up included regular assessment of clinical status, routine biochemical parameters and endocrine biology. Patients were hospitalised and great attention was paid to symptomatic treatment of co-morbidities including spironolactone and potassium supplementation, antihypertensive therapy and glucose-lowering oral drugs or insulin. As mitotane has been known to increase serum corticosteroid-binding globulin (CBG) concentration (not measured in this study), and thereby increasing total serum cortisol concentration (21), we monitored cortisol secretion using its urinary excretion. In some patients, salivary cortisol was also assayed to circumvent the increase in CBG levels $(22,23)$.

\section{Hormonal evaluation}

Serum cortisol and ACTH, UFC, and urinary creatinine were measured $(24,25)$ at Bicêtre and Bordeaux hospitals. The choice of assay kits and procedures aimed at preventing 11-deoxycortisol cross-reactivity with cortisol immunoassays $(26,27)$. Urinary cortisol was measured by a specific RIA using polyclonal antibodies (Orion Diagnostica, Spectria, Espoo, Finland) after dichloromethane extraction and celite chromatography. The intra- and inter-assay coefficient of variation (CV) values were lower than $7 \%$. The limit of quantification was $5 \mu \mathrm{g} / \mathrm{l}$ at Bicêtre and $8 \mu \mathrm{g} / \mathrm{l}$ at Bordeaux. The normal range of UFC excretion was $10-65 \mu \mathrm{g} /$ day at Bicêtre (24) and 15-80 $\mu \mathrm{g} /$ day at Bordeaux. The accuracy of urine specimen collection was verified by measuring $24-\mathrm{h}$ urinary creatinine excretion. Serum cortisol concentrations were measured by a chemiluminescent competitive immunoassay using a polyclonal antibody (at Bicêtre Immulite; Siemens, Deerfield, MI, USA and at Bordeaux DXi, Beckman-Coulter, France) and a RIA assay (Gamma Coat; Dia Sorin, Stillwater, MN, USA) at Bordeaux. The intraand inter-assay $\mathrm{CV}$ values were $<8 \%$. The limit of quantification was $6 \mathrm{nmol} / \mathrm{l}$ at Bicêtre and $12 \mathrm{nmol} / \mathrm{l}$ at Bordeaux. ACTH concentrations were determined at Bicêtre with a chemiluminescent assay (Siemens Healthcare Diagnostics Products, Llanberis, UK) and at Bordeaux by an IRMA 


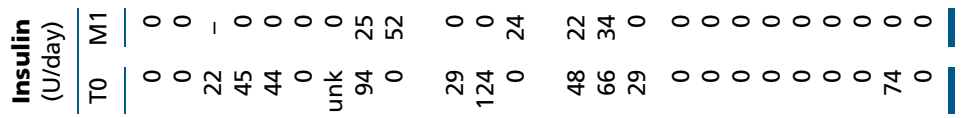

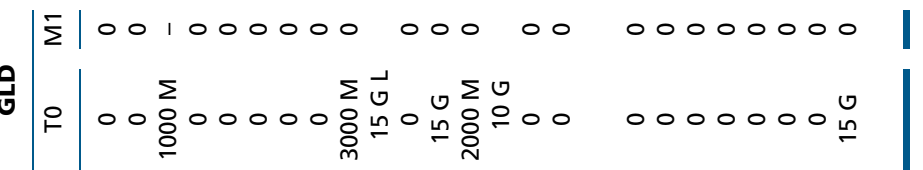

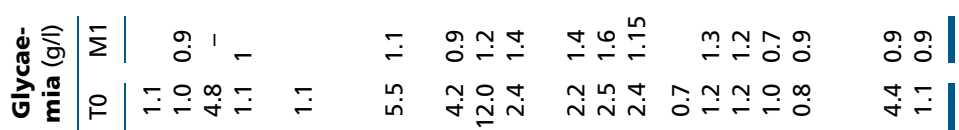

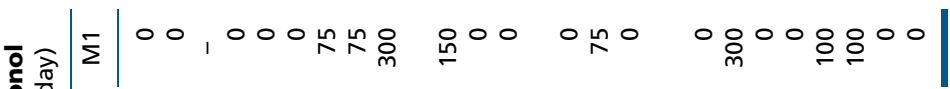

ทें है

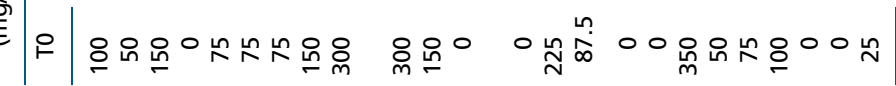

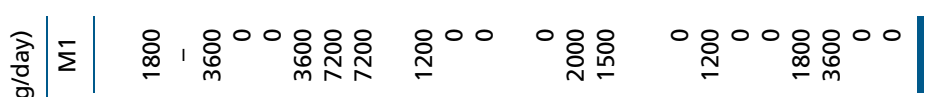

ป̄

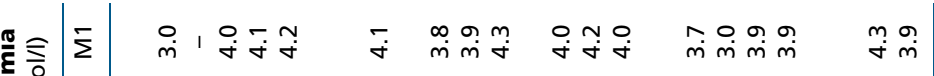

药

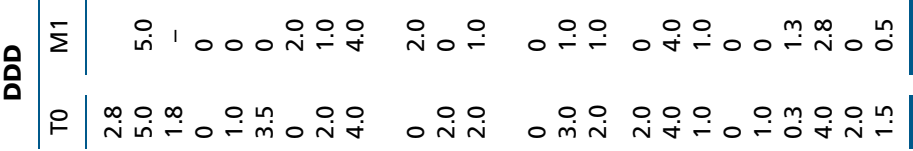

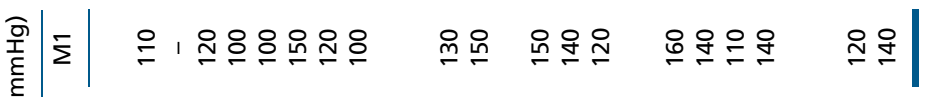

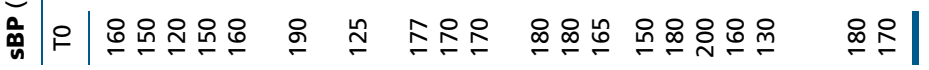

㲠|

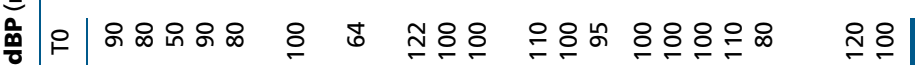

$\stackrel{-1}{\circ}$

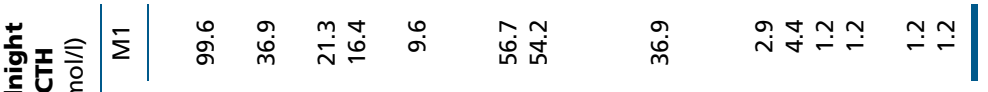

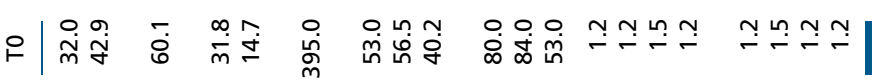

i

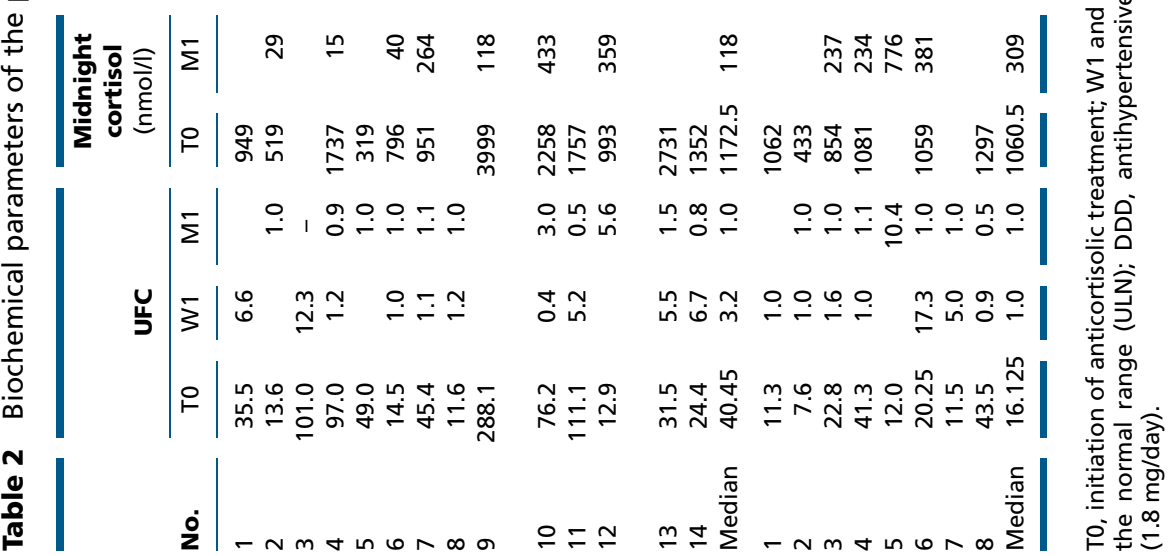


assay (ACTH RIA, B.R.A.H.M.S., Asnière sur Seine, France). The intra- and inter-assay $C V$ values were $<5 \%$. The limit of quantification was $1.1 \mathrm{pmol} / \mathrm{l}$ at Bicêtre and $1.2 \mathrm{pmol} / \mathrm{l}$ at Bordeaux.

\section{Statistical analysis}

Daily drug dosage (DDD), based on tables of equivalent antihypertensive power for the various antihypertensive drugs available at their various doses to enable comparison, was used for calculations (28). The DDD tables originate from the hypertension unit of Pompidou European Hospital (Paris, France).

The results are expressed as medians and ranges. The Wilcoxon signed-rank and $\chi^{2}$ tests were used, as appropriate. The $P$ values $<0.05$ were considered statistically significant.

\section{Results}

\section{Patients with EAS}

Median UFC dramatically decreased from $40(12 ; 288)$ ULN at baseline to $3.2(0.4 ; 12.3)$ ULN after 1 week (Fig. 1$)$, when $50 \%$ of patients had normal UFC values ( $\leq 1.2 \mathrm{ULN}$ ). One patient (\#3) with small-cell lung cancer died within 1 month of metastatic spread. Despite sustained elevated plasma ACTH concentrations (median 53 pmol/l, Table 2), a 96\% median decrease in UFC level was observed after 1 month of treatment. Median UFC was 0.5 ULN, and values were normal in $73 \%$ of patients. A similar trend was observed for midnight plasma cortisol. Hydrocortisone had to be introduced in two patients (\#4 and \#6 after 0.1 and 0.3 months respectively). A rapid and dramatic improvement in clinical status and the relevant endpoints closely followed biological regression of hypercortisolism. One month after treatment initiation, the median kalaemia had risen from $2.6(1.8 ; 4.0)$ to $4.0(3.0 ; 4.3)$ $\mathrm{mmol} / \mathrm{l}$, in parallel with a reduction in potassium supplementation and the spironolactone dosage $(P<0.05)$. The prevalence of hypokalaemia fell from 92 to $10 \%$. Systolic and diastolic blood pressure (sBP and dBP) fell from $165(120 ; 190)$ to $120(100 ; 150) \mathrm{mmHg}$ and from $95(50 ; 122)$ to $80(50 ; 90) \mathrm{mmHg}$ respectively $(P<0.01$ and $P<0.05)$, in parallel with a non-significant reduction in DDD. The prevalence of hypertension requiring drug treatment fell from 83 to $58 \%$. Fasting blood glucose fell from $13.2(5.5 ; 66.0)$ to $6.6(5.0 ; 8.8) \mathrm{mmol} / \mathrm{l}$, in parallel with a reduction in glucose-lowering drug use. The prevalence of diabetes requiring drug treatment fell from 78 to $50 \%$.
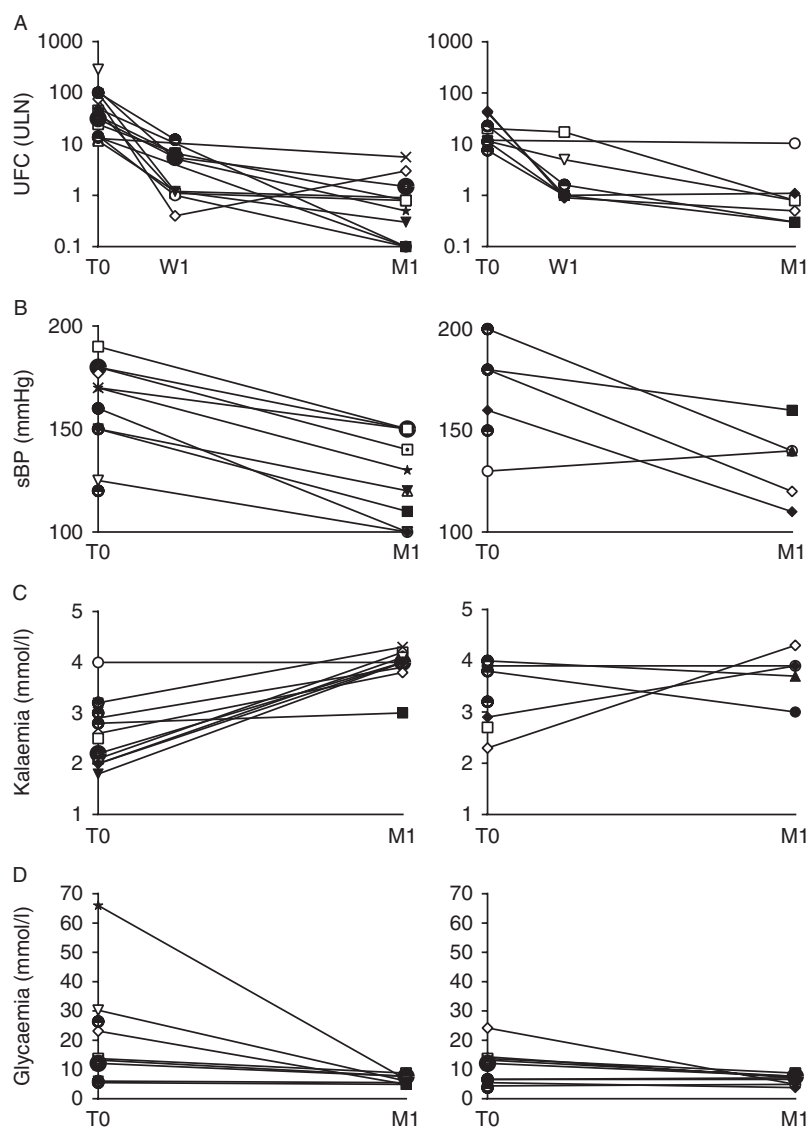

\section{Figure 1}

Time course of urinary free cortisol (UFC) (A), systolic blood pressure (sBP) (B), kalaemia (C) and glycaemia (D) in patients with ectopic ACTH syndrome (left panels) and adrenal carcinomas (right panels). TO, initiation of anticortisolic treatment; $\mathrm{W} 1$ and $\mathrm{M} 1,1$ week and 1 month after initiation of anticortisolic treatment respectively.

Plasma transaminase increased in one patient (EAS\#8, undocumented) necessitating ketoconazole discontinuation. This patient died of cancer with hepatic metastasis 2 months after the commencing medical therapy despite chemotherapy. No data are available regarding his liver biochemical parameters. Out of 14 patients, five complained of mild nausea.

\section{Patients with ACC}

Baseline median UFC dramatically decreased from 16 $(8 ; 44)$ ULN at baseline to $1.0(0.9 ; 17.3)$ ULN after 1 week (Fig. 1), when $75 \%$ of patients had normal UFC values.

A 94\% median decrease in UFC was observed after 1 month of treatment with a median UFC of $1.0 \mathrm{ULN}$, when 
$86 \%$ of patients had normal values. A similar trend was observed for midnight plasma cortisol (Table 2). Additive hydrocortisone supplementation had to be introduced in two cases (\#1 and \#8, after 0.3 and 0.1 month respectively). Plasma ACTH concentrations after 1 month remained suppressed in most of the patients. Relevant endpoints such as kalaemia, glycaemia and BP improved rapidly. One month after treatment initiation, the median kalaemia had risen from $3.2(2.3 ; 4.0)$ to $3.9(3.0 ; 4.3) \mathrm{mmol} / \mathrm{l}$, in parallel with a non-significant trend towards reduction in potassium supplementation and the spironolactone dosage. The prevalence of hypokalaemia fell from 57 to $20 \%$ sBP and dBP decreased from $170(130 ; 200)$ to $140(110 ; 160) \mathrm{mmHg}$ and from $100(80 ; 120)$ to $80(70 ; 90) \mathrm{mmHg}$, respectively (NS), in parallel with a reduction in DDD from $1.5(0.0 ; 4.0)$ to $0.5(0.0 ; 4.0)$ (NS). The prevalence of hypertension requiring drug treatment fell from 88 to $50 \%$. Fasting blood glucose fell from $6.1(3.9 ; 24.2)$ to $5.0(3.9 ; 7.2)$ $\mathrm{mmol} / \mathrm{l}$, in parallel with a reduction in glucose-lowering drug use. The prevalence of diabetes requiring drug treatment was not significantly changed (12\%).

Plasma ASAT and ALAT levels increased up to two and five ULN, respectively, in one patient (ACC\#1) necessitating discontinuation of ketoconazole. The patient underwent successful surgical resection of the ACC within 2 months after commencing medical therapy, and plasma transaminases returned to normal levels. Out of eight patients, six complained of mild nausea.

\section{Follow-up}

As indicated, one patient died within the study period, i.e. 1 month.

Six patients with ACC died within the first year as they had unresectable ACC associated with progression of the disease despite chemotherapy; the two other patients were operated for ACC, received mitotane as adjuvant therapy and are free of the disease after 4 years of follow-up.

The four patients with EAS due to bronchial carcinoids underwent successful resection of their tumour and were cured of CS. Nine patients had unresectable ACTHsecreting tumours and underwent BLA associated with cytotoxic chemotherapy. The source of ACTH is still occult in one patient (EAS\#4) who is in remission from CS using mitotane treatment exclusively.

\section{Discussion}

Severe hypercortisolism is associated with life-threatening acute disorders $(10,11)$. Despite variations among the patients in the dosage protocol used, we demonstrate that relatively high doses of metyrapone and ketoconazole used in combination dramatically decrease cortisol production within 1 week in all EAS patients and provide control of hypercortisolism at 1 month in a majority of EAS patients. In line with a previous report involving a small number of patients (24), we also observed that the decrease in cortisol production was associated with a rapid and dramatic clinical improvement, as illustrated by the control of hypertension, hypokalaemia and hyperglycaemia allowing a reduction in the dosages of drugs used to treat these disorders. Adrenal insufficiency, defined as low ( $<160 \mathrm{nmol} / \mathrm{l}) 0800 \mathrm{~h}$ serum cortisol measured during the follow-up, occurred in $15 \%$ of patients, but it may be considered as a therapeutic objective rather than an adverse effect in this setting. Despite the methodological caveats due to the retrospective design of our study that hampers any dose-response evaluation, it is noteworthy that the initial prescribed dose required only marginal adjustment in most patients, and that, at least during the first month of treatment, steroidogenesis blockade was not overcome by ACTH secretion.

To date, the impact of this combination therapy has only been reported in rare cases of ACC. Our study demonstrates that a roughly similar benefit to that obtained in EAS can be expected. The relatively inferior improvement in hypokalaemia in ACC patients might be related to the synthesis of mineralocorticoid precursors by ACC that was not targeted by ketoconazole and metyrapone (3). Efforts have been made in the recent years to improve the prognosis of ACC (29). However, the only chance of prolonged survival in these patients is complete surgical removal. In patients with non-resectable cortisolsecreting ACCs, a dramatic improvement in glucocorticoid secretion is crucial, as severe hypercortisolism may increase the prevalence of severe infections during chemotherapy (30) and has also been identified as an additional factor of bad prognosis $(9,31)$.

Mitotane, a powerful adrenolytic drug, was introduced concomitantly with metyrapone and ketoconazole in a few of the EAS patients and roughly half of the ACC patients in our study. Although mitotane as monotherapy has been shown to be useful to control hypercortisolism in the long term, we believe that it is unlikely to have contributed much to the short-term control of hypercortisolism observed herein, as its antisecretory effect takes several months to emerge $((1,22,32)$, and Salenave et al. manuscript in preparation). In Cushing's disease, the delay to obtain remission was 6.7 months with no remission at 1 month (32). In patients with ectopic 
ACTH secretion that were treated using solely mitotane, the time needed to achieve a normal urinary cortisol level on mitotane therapy was $130 \pm 85$ days (range 16-307) (16). Mitotane was administered to all patients with ACC, but its introduction was sometimes delayed by a few days or weeks (Tables 1 and 2), as severe hypercortisolism was considered the most urgent problem to solve and as some patients could hardly ingest the total amount of pellets prescribed.

The adverse effects of metyrapone and ketoconazole consisted mainly of mild gastrointestinal disorders. Transaminase elevations occurred in two out of 22 patients and were reversible after ketoconazole discontinuation. Castinetti et al. (17) reported such effects in $<5 \%$ of patients in a large series of patients with Cushing's disease. Although the median doses of ketoconazole used in our patients were greater than that used in the large series of patients included in the study by Castinetti et al. (17), our data confirm the relatively good liver tolerance of ketoconazole at high doses. Interestingly, in three patients with elevated transaminase levels at baseline, possibly due to the impact of severe hypercortisolism on the liver, we observed a significant improvement in liver function test results. Although close monitoring of liver function is mandatory during ketoconazole treatment, our data indicate that abnormal liver function at baseline should not preclude the use of this drug in this setting. Notably, hypokalaemia improved in all patients and we never observed worsening of hypokalaemia due to metyraponeinduced deoxycorticosterone production.

One main study has described the effectiveness of metyrapone monotherapy to control hypercortisolism in ten out of 16 patients with EAS but lacks detailed information on the clinical improvement of patients (4). Notably, median doses of metyrapone used to control hypercortisolism were $4000 \mathrm{mg} / \mathrm{day}$, e.g. approximately twice those used in our study. Gastrointestinal intolerance, e.g. the most prevalent and potentially limiting side effect of metyrapone, as well as metyrapone-induced deoxycorticosterone secretion resulting in hypokalaemia may increase at such doses (33). The synergistic action of ketoconazole that acts on distinct steroidogenic enzymes may allow a better control of hypercortisolism with reduction of metyrapone dosage together with an improved tolerance (2). Concordantly, ketoconazole monotherapy, even at high doses, may only partly control severe hypercortisolism $(10,11,32)$, an observation that reinforces the relevance of a combined medical strategy.

Bilateral adrenalectomy (BLA) may be an alternative option in patients with EAS $(34,35)$. Despite the improvement in morbidity and mortality due to the development of laparoscopic approaches, a recent review has pinpointed the frequency of post-operative deaths in patients with EAS, which are likely to be due to the consequences of severe hypercortisolism (36). We can speculate that a transient treatment with metyraponeketoconazole combination therapy in patients that are candidate to BLA may improve their general condition and, consequently, surgical morbidity (including wound infection and impaired wound healing) and mortality. This hypothesis is consistent with the recent series acknowledging the safety of BLA in EAS but in which a majority of patients underwent medical treatment for CS before surgery $(34,35)$. Although our study focused on the short-term usefulness of the metyrapone-ketoconazole combination therapy, this regimen may also be effective in the mid- to long term (24) and prevent BLA patients with occult ACTH-secreting tumours. These cases that account for $13-26 \%$ of patients in a large recent series are usually bronchial carcinoids that are often identified and surgically removed during follow-up $(10,11,37,38)$.

In conclusion, this study demonstrates that metyrapone-ketoconazole combination therapy is well tolerated and rapidly controls life-threatening severe hypercortisolism secondary to endocrine neoplasms. In patients with ACC, it may rapidly improve the patient's condition before surgery or reduce the risk of hypercortisolism-induced side effects associated with antineoplastic chemotherapy (13). In patients with occult EAS or unresectable neoplasm, this treatment therefore represents an alternative to BLA (24). Various initiation dosages have been proposed for CS (33). Based on our data, starting doses of $2500 \mathrm{mg} /$ day metyrapone and $1000 \mathrm{mg} /$ day ketoconazole may be proposed when UFC is $>5$ ULN. Multiple daily measurements of plasma cortisol have been proposed to monitor steroidogenesis inhibition (4). Our study suggests that UFC and 8-h plasma cortisol measurement using appropriate assays with minimal cross-reactivity with 11-deoxycortisol performed within 1 week after initiation of the treatment is a reasonable alternative.

Declaration of interest

The authors declare that there is no conflict of interest that could be perceived as prejudicing the impartiality of the research reported.

Funding

This research did not receive any specific grant from any funding agency in the public, commercial or not-for-profit sector. 


\section{References}

1 Newell-Price J, Bertagna X, Grossman AB \& Nieman LK. Cushing's syndrome. Lancet 2006367 1605-1617. (doi:10.1016/S01406736(06)68699-6)

2 Feelders RA, Hofland LJ \& de Herder WW. Medical treatment of Cushing's syndrome: adrenal-blocking drugs and ketaconazole. Neuroendocrinology 201092 (Suppl 1) 111-115. (doi:10.1159/000314292)

3 Arlt W, Biehl M, Taylor AE, Hahner S, Libe R, Hughes BA, Schneider P, Smith DJ, Stiekema H, Krone $\mathrm{N}$ et al. Urine steroid metabolomics as a biomarker tool for detecting malignancy in adrenal tumors. Journal of Clinical Endocrinology and Metabolism 201196 3775-3784. (doi:10.1210/ jc.2011-1565)

4 Verhelst JA, Trainer PJ, Howlett TA, Perry L, Rees LH, Grossman AB, Wass JA \& Besser GM. Short and long-term responses to metyrapone in the medical management of 91 patients with Cushing's syndrome. Clinical Endocrinology 199135 169-178. (doi:10.1111/j.1365-2265. 1991.tb03517.x)

5 Sonino N, Fallo F \& Fava GA. Psychosomatic aspects of Cushing's syndrome. Reviews in Endocrine \& Metabolic Disorders 201011 95-104. (doi:10.1007/s11154-009-9123-7)

6 Yanovski JA \& Cutler GB Jr. Glucocorticoid action and the clinical features of Cushing's syndrome. Endocrinology and Metabolism Clinics of North America 199423 487-509.

7 Arlt A, Harbeck B, Anlauf M, Alkatout I, Kloppel G, Folsch UR, Bewig B \& Monig H. Fatal pneumocystis jirovecii pneumonia in a case of ectopic Cushing's syndrome due to neuroendocrine carcinoma of the kidney. Experimental and Clinical Endocrinology \& Diabetes 2008116 515-519. (doi:10.1055/s-2008-1062729)

8 van der Pas R, Leebeek FW, Hofland LJ, de Herder WW \& Feelders RA. Hypercoagulability in Cushing's syndrome: prevalence, pathogenesis and treatment. Clinical Endocrinology 201378 481-488. (doi:10.1111/ cen.12094)

9 Abiven G, Coste J, Groussin L, Anract P, Tissier F, Legmann P, Dousset B, Bertagna X \& Bertherat J. Clinical and biological features in the prognosis of adrenocortical cancer: poor outcome of cortisol-secreting tumors in a series of 202 consecutive patients. Journal of Clinical Endocrinology and Metabolism 200691 2650-2655. (doi:10.1210/jc. 2005-2730)

10 Ejaz S, Vassilopoulou-Sellin R, Busaidy NL, Hu MI, Waguespack SG, Jimenez C, Ying AK, Cabanillas M, Abbara M \& Habra MA. Cushing's syndrome secondary to ectopic adrenocorticotropic hormone secretion: the University of Texas MD Anderson Cancer Center Experience. Cancer 2011117 4381-4389. (doi:10.1002/cncr.26029)

11 Ilias I, Torpy DJ, Pacak K, Mullen N, Wesley RA \& Nieman LK. Cushing's syndrome due to ectopic corticotropin secretion: twenty years' experience at the National Institutes of Health. Journal of Clinical Endocrinology and Metabolism 200590 4955-4962. (doi:10.1210/jc. 2004-2527)

12 Nagy-Mignotte H, Shestaeva O, Vignoud L, Guillem P, Ruckly S, Chabre O, Sakhri L, Duruisseaux M, Mousseau M, Timsit JF et al. Prognostic impact of paraneoplastic Cushing's syndrome in small-cell lung cancer. Journal of Thoracic Oncology 20149 497-505. (doi:10.1097/ JTO.0000000000000116)

13 Collichio FA, Woolf PD \& Brower M. Management of patients with small cell carcinoma and the syndrome of ectopic corticotropin secretion. Cancer 199473 1361-1367. (doi:10.1002/1097-0142 (19940301)73:5 < 1361::AID-CNCR2820730509>3.0.CO;2-J)

14 Vassilopoulou-Sellin R. Paraneoplastic hypercortisolism as a risk factor for severe infections in patients with malignant diseases. Journal of Clinical Endocrinology and Metabolism 200186 947-948. (doi:10.1210/ jcem.86.2.7241-5)

15 Castinetti F, Fassnacht M, Johanssen S, Terzolo M, Bouchard P, Chanson P, Do Cao C, Morange I, Pico A, Ouzounian S et al. Merits and pitfalls of mifepristone in Cushing's syndrome. European Journal of Endocrinology 2009160 1003-1010. (doi:10.1530/EJE-09-0098)

16 Preda VA, Sen J, Karavitaki N \& Grossman AB. Etomidate in the management of hypercortisolaemia in Cushing's syndrome: a review. European Journal of Endocrinology 2012167 137-143. (doi:10.1530/ EJE-12-0746)

17 Castinetti F, Guignat L, Giraud P, Muller M, Kamenicky P, Drui D, Caron P, Luca F, Donadille B, Vantyghem MC et al. Ketoconazole in Cushing's disease: is it worth a try? Journal of Clinical Endocrinology and Metabolism 201499 1623-1630. (doi:10.1210/jc.2013-3628)

18 Tabarin A, Navarranne A, Guerin J, Corcuff JB, Parneix M \& Roger P. Use of ketoconazole in the treatment of Cushing's disease and ectopic ACTH syndrome. Clinical Endocrinology 199134 63-69. (doi:10.1111/ j.1365-2265.1991.tb01737.x)

19 Sonino N, Boscaro M, Paoletta A, Mantero F \& Ziliotto D. Ketoconazole treatment in Cushing's syndrome: experience in 34 patients. Clinical Endocrinology 199135 347-352. (doi:10.1111/j.1365-2265.1991. tb03547.x)

20 Else T, Kim AC, Sabolch A, Raymond VM, Kandathil A, Caoili EM, Jolly S, Miller BS, Giordano TJ \& Hammer GD. Adrenocortical carcinoma. Endocrine Reviews 201435 282-326. (doi:10.1210/er.20131029)

21 Nader N, Raverot G, Emptoz-Bonneton A, Dechaud H, Bonnay M, Baudin E \& Pugeat M. Mitotane has an estrogenic effect on sex hormone-binding globulin and corticosteroid-binding globulin in humans. Journal of Clinical Endocrinology and Metabolism 200691 2165-2170. (doi:10.1210/jc.2005-2157)

22 Donadille B, Groussin L, Waintrop C, Abbas H, Tenenbaum F, Dugue MA, Coste J, Bertagna X \& Bertherat J. Management of Cushing's syndrome due to ectopic adrenocorticotropin secretion with 1,ortho-1, para'-dichloro-diphenyl-dichloro-ethane: findings in 23 patients from a single center. Journal of Clinical Endocrinology and Metabolism 201095 537-544. (doi:10.1210/jc.2009-1317)

23 Carrozza C, Lapolla R, Gervasoni J, Rota CA, Locantore P, Pontecorvi A, Zuppi C \& Persichilli S. Assessment of salivary free cortisol levels by liquid chromatography with tandem mass spectrometry (LC-MS/MS) in patients treated with mitotane. Hormones 201211 344-349. (doi:10.14310/horm.2002.1363)

24 Kamenicky P, Droumaguet C, Salenave S, Blanchard A, Jublanc C, Gautier JF, Brailly-Tabard S, Leboulleux S, Schlumberger M, Baudin E et al. Mitotane, metyrapone, and ketoconazole combination therapy as an alternative to rescue adrenalectomy for severe ACTH-dependent Cushing's syndrome. Journal of Clinical Endocrinology and Metabolism 201196 2796-2804. (doi:10.1210/jc.2011-0536)

25 More J, Young J, Reznik Y, Raverot G, Borson-Chazot F, Rohmer V, Baudin E, Coutant R, Tabarin A \& Groupe Francais des Tumeurs Endocrines. Ectopic ACTH syndrome in children and adolescents. Journal of Clinical Endocrinology and Metabolism 201196 1213-1222. (doi:10.1210/jc.2010-2276)

26 Monaghan PJ, Owen LJ, Trainer PJ, Brabant G, Keevil BG \& Darby D Comparison of serum cortisol measurement by immunoassay and liquid chromatography-tandem mass spectrometry in patients receiving the 11ß-hydroxylase inhibitor metyrapone. Annals of Clinical Biochemistry 201148 441-446. (doi:10.1258/acb.2011.011014)

27 Brossaud J, Barat P, Georges A \& Corcuff JB. Impact of the reference values on the clinically-relevant cut-offs. The example of cortisol testing in children. Clinical Chemistry and Laboratory Medicine 201250 901-903. (doi:10.1515/cclm-2012-0142)

28 Maxwell M, Heaney D, Howie JG \& Noble S. General practice fundholding: observations on prescribing patterns and costs using the defined daily dose method. BMJ 1993307 1190-1194. (doi:10.1136/ bmj.307.6913.1190)

29 Ronchi CL, Kroiss M, Sbiera S, Deutschbein T \& Fassnacht M. EJE prize 2014: current and evolving treatment options in adrenocortical carcinoma: where do we stand and where do we want to go? 
European Journal of Endocrinology 2014171 R1-R11. (doi:10.1530/ EJE-14-0273)

30 Sarlis NJ, Chanock SJ \& Nieman LK. Cortisolemic indices predict severe infections in Cushing's syndrome due to ectopic production of adrenocorticotropin. Journal of Clinical Endocrinology and Metabolism 200085 42-47. (doi:10.1210/jcem.85.1.6294)

31 Berruti A, Terzolo M, Sperone P, Pia A, Della Casa S, Gross DJ, Carnaghi C, Casali P, Porpiglia F, Mantero F et al. Etoposide, doxorubicin and cisplatin plus mitotane in the treatment of advanced adrenocortical carcinoma: a large prospective phase II trial. EndocrineRelated Cancer 200512 657-666. (doi:10.1677/erc.1.01025)

32 Baudry C, Coste J, Bou Khalil R, Silvera S, Guignat L, Guibourdenche J, Abbas H, Legmann P, Bertagna X \& Bertherat J. Efficiency and tolerance of mitotane in Cushing's disease in 76 patients from a single center. European Journal of Endocrinology 2012167 473-481. (doi:10.1530/ EJE-12-0358)

33 Biller BM, Grossman AB, Stewart PM, Melmed S, Bertagna X, Bertherat J, Buchfelder M, Colao A, Hermus AR, Hofland LJ et al. Treatment of adrenocorticotropin-dependent Cushing's syndrome: a consensus statement. Journal of Clinical Endocrinology and Metabolism 200893 2454-2462. (doi:10.1210/jc.2007-2734)
34 Alberda WJ, van Eijck CH, Feelders RA, Kazemier G, de Herder WW \& Burger JW. Endoscopic bilateral adrenalectomy in patients with ectopic Cushing's syndrome. Surgical Endoscopy 201226 1140-1145. (doi:10. 1007/s00464-011-2020-7)

35 Chow JT, Thompson GB, Grant CS, Farley DR, Richards ML \& Young WF Jr. Bilateral laparoscopic adrenalectomy for corticotrophindependent Cushing's syndrome: a review of the Mayo Clinic experience. Clinical Endocrinology 200868 513-519. (doi:10.1111/j. 1365-2265.2007.03082.x)

36 Ritzel K, Beuschlein F, Mickisch A, Osswald A, Schneider HJ, Schopohl J \& Reincke M. Clinical review: Outcome of bilateral adrenalectomy in Cushing's syndrome: a systematic review. Journal of Clinical Endocrinology and Metabolism 201398 3939-3948. (doi:10.1210/jc.2013-1470)

37 Isidori AM, Kaltsas GA, Pozza C, Frajese V, Newell-Price J, Reznek RH, Jenkins PJ, Monson JP, Grossman AB \& Besser GM. The ectopic adrenocorticotropin syndrome: clinical features, diagnosis, management, and long-term follow-up. Journal of Clinical Endocrinology and Metabolism 200691 371-377. (doi:10.1210/jc.2005-1542)

38 Aniszewski JP, Young WF Jr, Thompson GB, Grant CS \& van Heerden JA. Cushing's syndrome due to ectopic adrenocorticotropic hormone secretion. World Journal of Surgery 200125 934-940. (doi:10. 1007/s00268-001-0032-5)

Received 24 October 2014

Revised version received 6 January 2015

Accepted 14 January 2015 